\title{
CONSEQUENCES OF MODELING DRAFT TILLAGE FORCE ON DYNAMICS OF SOIL TILLAGE AGRICULTURAL MACHINERY
}

\author{
Petru Cardei ${ }^{1}$, Sorin-Stefan Biris ${ }^{2}$, Sebastian Muraru ${ }^{1}$, Marius Oprescu ${ }^{1}$ \\ ${ }^{1}$ National Institute of Research-Development for Machines and Installations Designed to Agriculture \\ and Food Industry, Romania; ${ }^{2}$ University Politehnica of Bucharest, Romania \\ petru_cardei@yahoo.com, biris.sorinstefan@gmail.com
}

\begin{abstract}
The paper presents consequences of the use in solving the equation of motion of an agricultural aggregate for tillage of different forms of the soil draft tillage force. The consequences of the dependence of the soil draft tillage force by the working speed, as well as the effect and acceptance of purely static terms, are investigated. Methods are given to modify the static terms in the equation of motion of the aggregate. The problem refers especially to the terms related to friction and to those that give the force of resistance to soil deformation. These component terms of the tensile strength can give various paradoxical interpretations, which are not found in experimental research, which is why various alternative forms are proposed for their remodelling. The proposed new forms lead to solutions of the equations of moving closer to reality, first of all, in the stages of transition, starting from repose and braking until repose. Two ways of correcting the expressions of tensile strength forces are exploited: the introduction of test-type operators, respectively the proposal of models of tensile strength forces that depend on a positive power, not necessarily the whole, of the travel speed. The consequences of these functions on the working regime of the aggregate are studied, and also on the numerical apparatus involved in solving the dynamic problem. The results highlight the complexity of the agricultural unit, which, in addition to the mechanical component, also includes a partially random component, the human component, and the driver of the vehicle. Through commands, this last component of the system can improve or worsen the characteristics of the work process.
\end{abstract}

Keywords: soil, tillage, draft, force, dynamics.

\section{Introduction}

The latest mathematical models of vehicles and their working process are those based on the systems theory, [1-3]. Such mathematical models are presented, for example, in [4-7] and some are based on software programs for simulating vehicle operation. Vehicle dynamics is a very complex scientific discipline, [8]. The study of equations of motion is an important part of vehicle dynamics. Solving these equations provides conditions for stability of the vehicle, for the general behaviour, when travelling on different types of terrain and environmental conditions.

For agricultural machinery, the dynamics of the vehicles is important at least for achieving optimal working conditions or for the safety of the large transport. The complete characterization of the vehicles as systems imposes the need to simulate complete movements, including the transitive regimes of starting from rest and braking until the state of rest or change of speed. Other phenomena, such as stability, need to be re-evaluated under such conditions. From this point of view, it is inevitable to describe a very important subsystem of the vehicle: the man with the control systems (acceleration, braking, steering) and possible automatic adjustment subsystems.

The interest in the aspects described above for the users of vehicles used in agriculture, results from the need to increase the accuracy of the mathematical modelling of the resistance forces generated by the contact with the environment. Examples are the friction forces between the machine and the ground or the forces of resistance to tillage. Current models of these resistance forces are expressed as functions that depend on the working speed of the agricultural unit. Many of the functions that model the resistance forces for soil tillage aggregates are second-degree polynomial functions, complete or incomplete, [913]. A partial synthesis of these mathematical models can be found in [14]. Research on the behaviour of soil particles to determine the tensile forces $[15 ; 16]$, used in the study of modelling the forces acting on soils, was conducted by $[17 ; 18]$, respectively how they should be designed so as to have maximum efficiency in the work process [19].

In the research results given in this article we highlighted the effects of using different mathematical models for the resistance force in the equations of motion of vehicles, comparisons between the solutions obtained and with available experimental data. We evaluated the extent to which the shapes of the obtained forces can influence the quality of the works performed by the tillage aggregates. 


\section{Materials and methods}

The simplest mathematical model for a working aggregate, when it concerns only the dynamic aspects related to the trajectory and the way of moving on it, is that of the material point. The equation of motion is the one given by all the treatises on physics and mathematical physics, for example [20], known as the impulse theorem and coming from the original second law of dynamics. To simplify, we will only deal with the case of rectilinear displacement, often characteristic of agricultural aggregates intended for soil tillage. For this case, the motion can be considered to be described by the equation:

$$
m \ddot{x}=F(t, x, \dot{x}),
$$

where $m$-mass;

$F-$ force;

$t$ - time;

$x$ - is the space (with one and two points above it represents speed and acceleration), with the initial conditions null, for a resting aggregate

$$
x\left(t_{0}\right)=x_{0}=0, \dot{x}\left(t_{0}\right)=v_{0}=0 .
$$

The time $t_{0}$ can be taken 0 . Under these conditions the equation of motion of the material point that models the movement of the aggregate (the centre of mass of the aggregate can be taken) is written as (1), using the expression (3) of the force:

$$
F(t, x, \dot{x})=F_{t}(t)-R(t, x, \dot{x})
$$

where $F_{t}$-force at the traction wheels, force which has the quality of control over the travel regime;

$R$-force of traction resistance exerted on the aggregate (the resultant in the centre of mass).

For a transport vehicle, the resistance force is considered to be the friction of the tires with the road:

$$
R(t, x, \dot{x})=(M+m) g \varphi
$$

where $\quad M$ and $\mathrm{m}-$ masses of the tractor and trailer;

$g$ - gravitational acceleration;

$\varphi$ - coefficient of friction between the tires and the tread.

If the resistance force has the form (4), then this force acts constantly independently of time. If the traction force is cancelled at some point, the force (4) will continue to act and lead to an infinite movement, leading the vehicle in the opposite direction to the desired travel. One solution to cancel this effect of force (4) is to rewrite it in the form of:

$$
R(t, x, \dot{x})=(M+m) g \varphi H(\dot{x}) \frac{\operatorname{sign}(\dot{x})}{\dot{x}}, \dot{x} \neq 0
$$

where $H$-Heaviside's function of the argument; sign-sign function of the argument, [21].

The mathematical model of the dynamic friction coefficient can be complicated depending on the experimental data, [22]. The results of simulating a motion process for a vehicle using equations (1) (5) are given in the chapter dedicated to the results.

The following model will extend the previous model to an agricultural unit for soil work, in which, in addition to the friction resistance of the tractor, there is also the friction of the tillage equipment, as well as the "static" component and dependent on the speed of the same equipment.

The following is an elementary example for an aggregate consisting of a tractor and tillage equipment, [23; 24]. We assume that we are working on level ground. The model of the force of displacement resistance due to the equipment is taken by Goriacikin type, [25]:

$$
R_{e}(\dot{x}, \mu, k, \varepsilon, S)=\mu m g+\left(k+\varepsilon \dot{x}^{2}\right) S
$$

where $R_{e}$ - resistance to displacement of the equipment and the significance of the other parameters is given in [25]. 
The alternative model is given by the formula:

$$
R_{e}(\dot{x}, \mu, k, \varepsilon, S)=\mu m g H(\dot{x})+\left(k H(\dot{x})+\varepsilon \dot{x}^{2}\right) S
$$

The equation of motion will, in this case, be given by the formula:

$$
(M+m) \ddot{x}=F_{t}(t)-R_{e}(\dot{x}, \mu, k, \varepsilon, S)-R(t, x, \dot{x})
$$

where $R$-given by (4) for the model using the machining strength (6) and (5) respectively when the machining strength is taken (7).

In the following example, the method of modifying the mathematical model of the resistance force to tillage will be applied to the statistical model of such a force, obtained from experimental data using the least squares method. The resistance force thus determined refers to the equipment for opening and partitioning watering channels. The expression of the theoretical-empirical force is, [26]:

$$
R_{e}(\dot{x})=952.589+3281.445 \dot{x}
$$

the modified form according to the method described above being:

$$
R_{e}(\dot{x})=952.589 \cdot H(\dot{x})+3281.445 \dot{x} .
$$

\section{Results and discussion}

To simulate the process of moving a vehicle between two consecutive rest states, a traction control function must be entered, without which the vehicle on a horizontal running path cannot be set in motion. The introduction of traction involves the consideration of the human subsystem of the vehicle system or of an automatic motion assistance system, which, however, must be programmed. Whichever of the two paths of application of the traction force would be chosen, we considered a traction function defined by the formula:

$$
F_{t}(t, v, x, L)=\left\{\begin{array}{l}
0, x>L \\
F_{a}(t, v), x \leq L
\end{array}\right.
$$

where

$$
F_{a}(t, v)=\left\{\begin{array}{l}
\alpha \cdot R_{s} \cdot t, v \leq v_{\min } \\
(1+\beta \sin (2 \cdot \pi \cdot \gamma \cdot t)) \cdot R_{s}, v>v_{\min } \text { and } t<c \cdot t_{\max } \\
0, \text { for all other situations }
\end{array}\right.
$$

where $\alpha, \beta, \gamma, v_{\min }, t_{\max }, c, L-$ control parameters required to drive the vehicle at cruising speed and to stop travel.

We also used the static resistance $R_{s}=M g \varphi$. For the simulation, the equations of motion were numerically integrated with the following values of the model parameters: $\alpha=2.0, \beta=0.05, \gamma=0.5$, $v_{\min }=0.99 \mathrm{~m} \cdot \mathrm{s}^{-1}, t_{\max }=10 \mathrm{~s}, c=0.85, L=8 \mathrm{~m}, M=3200 \mathrm{~kg}, m=0 \mathrm{~kg}, g=9.81 \mathrm{~m} \cdot \mathrm{s}^{-12}, \varphi=0.35$, $R_{s}=10987.2 \mathrm{~N} \cdot \mathrm{s}^{-1}$. Solving the equation of motion is done using a numerical method of Runge Kutta type. A constant step discretisation was used ( $\mathrm{N}=140,000$ steps). Fig. 1 shows the variations in space and speed for the two resistance cases considered, (7) and (8).

For the model of the aggregate formed with a tractor working with a tillage equipment, having the force of resistance to tillage given by models (5) and (6), results are obtained, by the same procedures, represented graphically in Fig. 2 . Using the above data, with the change $m=110 \mathrm{~kg}, L=6 \mathrm{~m}, \mu=0.5$, $k=40000 \mathrm{~Pa}, \rho=2000 \mathrm{~kg} \cdot \mathrm{m}^{-3}, S=0.083 \mathrm{~m}^{2}$ and the traction force given by (11) and (12), the solutions are represented graphically in Fig. 2. Numerical solving used the same calculation program with the same working parameters.

The case of the statistical mathematical model of the force of resistance to tillage (classical and modified variants by the method described above) is treated numerically similar to the cases which answers are given in Fig. 1 and 2. In this case, the number of parameters of the mathematical models of the resistance force to tillage is smaller, because the coefficients of the second degree polynomial, or of the extension of this model, are numerical constants deduced in the statistical processing process, (8) 
and (9). The dynamic responses of the aggregate to these force models are represented graphically in Fig. 3.

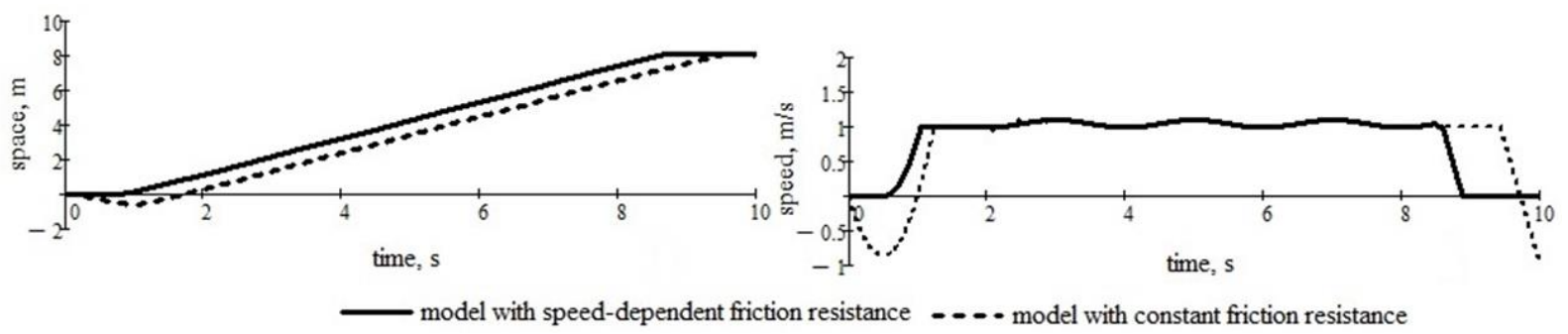

Fig. 1. Dependence of space and time speed for the two variants of resistance on movement of the vehicle
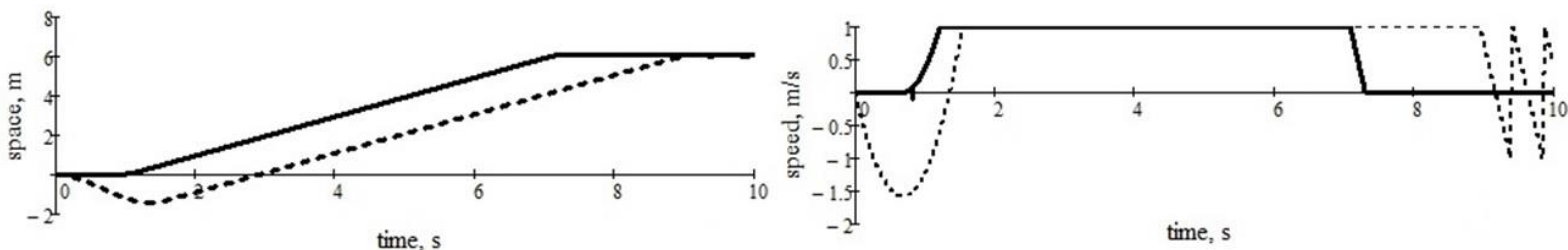

- model with integral speed-dependent draft tillage force - - model with partial-speed dependence of the draft tillage force

Fig. 2. Dependence of space and time speed for the two variants of resistance on displacement of the tractor - equipment for opening and compartmentalizing watering channels

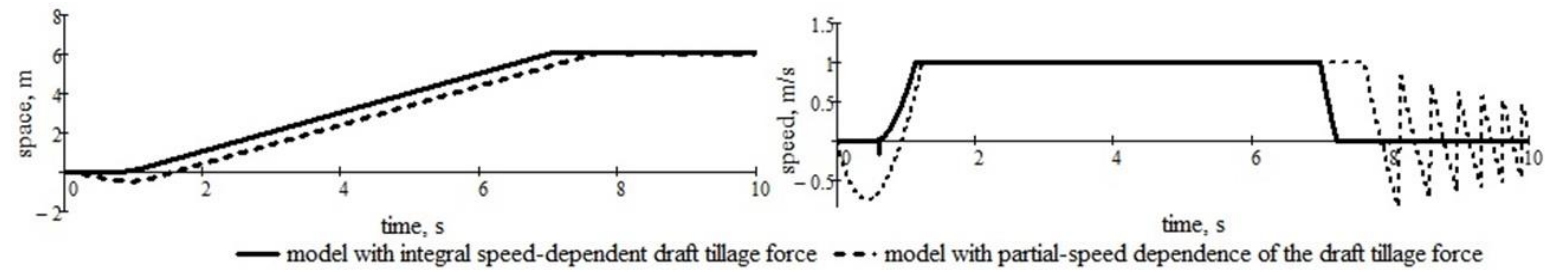

Fig. 3. Dependence of space and time speed for the two variants of resistance on displacement of the tractor unit - equipment for opening and compartmentalizing watering channels, in the variant of the statistical model

Considering the speed resistance model for a vehicle, dependent on speed, formula (8), compared to the classical model (7), leads to a better concordance of the theoretical result with the experiment. On the graphical representation of the solution of the equations of motion, given in Fig. 1, it is observed that the model (8) starts from rest, a state that is maintained until the traction force at the wheel (control) exceeds the value of the resistance given by the friction force, (8). The classical model shows the friction force (7) acting from the moment $t=0$, producing a negative speed and a reverse movement of the vehicle. Experimental model (8) leads to behaviour closer to the experimental one. In the range of approximately uniform motion (approximately constant speed), the two models have almost identical behaviour, which does not contradict the experiment. In the deceleration stage, produced only by cancelling the traction force (we did not impose an additional braking force), the model (8) leads to a decrease in speed to zero after which the vehicle stops, i.e. the distance travelled does not grow. The classic model continues the movement, the speed reaching negative values and implicitly the tendency to move in the opposite direction on the trajectory, which contradicts the experience.

For the model of the agricultural unit consisting of the tractor and the equipment for opening and compartmentalizing watering channels, the solutions given in the two variants of mathematical modelling present the same differences and similarities as in the case of the simple vehicle. The model in which the resistance to tillage and friction depends on the speed of movement is much closer to the experimental results, especially in the transient stages of movement areas where the classical model fails.

In the case of the processing the strength force model (classical and modified variant) deduced by statistical modelling using the least squares method applied to the experimental data, the results (Fig. 3), highlight the superiority of the modified variant. The superiority is manifested by a greater proximity to 
the experimental results, especially in the transient stages. For all the examples presented, it can be seen that the differences that motivate the proposed changes to the models of the force of resistance to tillage, are also important to the changes of the regime of movement or of the properties of the environment.

As we have not found similar approaches in the literature, we cannot compare our results with other answers to the same problems.

\section{Conclusions}

1. The research results presented in this article demonstrate that the choice of a type of model for the force of displacement resistance is important for obtaining a dynamic response close to reality. The dynamic response has important consequences in road or work behaviour: stability, energy consumption, manoeuvrability, quality of work performed, productivity, etc.

2. The research results show that the minimal change applied to the expressions of the forces of resistance to tillage leads to obtaining dynamic responses much more consistent with reality, especially in the transitional stages of the process of vehicle movement. At rest, the classic models, which contain static terms, develop a negative speed and a shift in the opposite direction to the desired one. When stopped by cancelling the traction force, the classic models continue to work and after cancelling the speed, it takes negative values and reverses the travel with possible oscillations. These phenomena are not observed experimentally or in the dynamic response to the proposed new models.

3. In addition to the effects of different models of resistance to displacement or tillage, on vehicle dynamics, the results of this research highlight the importance of control functions in the vehicle system, moreover, the importance of the vehicle control subsystem, which in most cases includes a component with some random behaviour, namely the human or the driver. A model variant for the control function is presented and used to generate the dynamic response of the vehicle. The modelled component is the traction force of the vehicle, apart from its steering and braking as control functions. These components of the control can be operated manually by the driver, also automatically by computerized systems equipped with sensors for sensing the road parameters.

4. Considering the conclusion 3 , more precisely the human control component, we suggest that at the experimental measurements of the traction force at an agricultural aggregate to be registered also the variation of the pressing force at the accelerator pedal. This additional recording could eliminate some errors in the tensile strength or could explain some variations of it.

\section{Acknowledgements}

This work was supported by a grant of the Ministry of Research, Innovation and Digitization (MRID), CCCDI - UEFISCDI, project number PN-III-P1-1.2-PCCDI-2017-0560 "Econanotechnologies and intelligent equipment for soil properties mapping and evaluating the dynamics of the plant in order to improve agricultural production and environmental protection, within PNCDI III and was done by "NUCLEU" Programme, developed with the support of MRID project PN 191001 02 .

\section{References}

[1] Voicu M., Teoria sistemelor (Systems theory), Romanian Academy Publishing House: Editura Academiei Romane, 2008. 416 p. (In Romanian)

[2] Ionescu V., Teoria sistemelor, sisteme liniare (Systems theory, linear systems), Didactic and Pedagogical Publishing House: Editura Didactica si Pedagogica, Bucuresti, 1985. 356 p. (In Romanian)

[3] Belea C., Teoria siatemelor, sisteme neliniare (Systems theory, nonlinear systems), Didactic and Pedagogical Publishing House: Editura Didactica si Pedagogica, Bucuresti, 1985. 344 p. (In Romanian)

[4] Sename O., Fergani S., Introduction to vehicle dynamics control, Grenoble, Tolouse, 2017. 127 p.

[5] Di Martino R., Modelling and simulation of the dynamic behaviour of the automobile, Mulhouse: Université de Haute Alsace - Mulhouse, 2005. 189 p.

[6] Dascalescu D., Dinamica autovehiculelor rutiere (Dynamics of road vehicles), Iasi: Politehnium, 2007. 268 p. (In Romanian) 
[7] Kienke U., Nielsen L., Automotive Control Systems For Engine, Driveline, and Vehicle, Berlin, Heidelberg: Springer, 2005. 521 p.

[8] Schramm D., Hiller M., Bardini R., Vehicle Dynamics:Modelling and Simulation, Springer-Verlag Berlin Heidelberg, 2014. 440 p.

[9] Tecuşan N., Ionescu E., Tractoare și automobile (Tractors and cars), Didactic and Pedagogical Publishing House: Editura Didactica și Pedagogica, 1982. 320 p. (In Romanian)

[10] Ghiulai C., Vasiliu Gh., Dinamica autovehiculelor (Vehicle dynamics), Didactic and Pedagogical Publishing House: Editura Didactica si Pedagogica, Bucuresti, 1975. 375 p. (In Romanian)

[11] Untaru M., Potincu Gh., Stoicescu A., Peres Gh., Tabacu I., Dinamica autovehiculelor pe roti (Dynamics of wheeled vehicles), Didactic and Pedagogical Publishing House: Editura Didactica si Pedagogica, București, 1981. 348 p. (In Romanian)

[12] Stoicescu A.P., Dinamica autovehiculelor (Vehicle Dynamics), Bucuresti, 1986. 251 p. (In Romanian)

[13] Moeenifar A., Mousavi-Seyedi S.,R., Kalantari D., Influence of tillage depth, penetration angle and forward speed on the soil/thin-blade interaction force, Agric Eng Int: CIGR Journal, vol. 16, no.1, 2014, pp. 69-74.

[14] Cardei P., Draft force on soil tillage, model tests and relative ordering, DOI: 10.13140/RG.2.2.11951.89769,

https://www.researchgate.net/publication/336836002_Draft_force_on_soil_tillage_model_tests_a nd_relative_ordering.

[15] Biriş S., Maican E., Vlăduţ V., Paraschiv G., Manea M., Bungescu S. - Study regarding the soil particles kinematics during the ante-mouldboard tillage tools working process, PROCEEDINGS OF THE 36 INTERNATIONAL SYMPOSIUM ON AGRICULTURAL ENGINEERING "Actual Tasks on Agricultural Engineering”, ISSN 1333-2651, Opatija - Croaţia, 2008, pp. 115-126.

[16] Croitoru Şt., Vlăduţ V., Marin E., Matache M., Dumitru I. - Determination of subsoiler's traction force influenced by different working depth and velocity, 15th International Scientific Conference “ENGINEERING FOR RURAL DEVELOPMENT", Proceedings, vol. 15, Jelgava, Latvia, 2016, , pp. 817-825.

[17] Ungureanu N., Vlăduţ V., Biriş S. Ș.- FEM modelling of soil behaviour under compressive loads, International Conference on Applied Sciences (ICAS2016), Hunedoara, Romania, May 25-27, 2016, Materials Science and Engineering, Vol 163, 012001, doi:10.1088/1757899X/163/1/012001, 2017, pp. 1-9.

[18] Ungureanu N., Vlăduţ V., Biriș S.Ș., Paraschiv G., Dincă M., Zăbavă B. Ș., Ștefan V., Gheorghiță N. E., FEM modelling of machinery induced compaction for the sustainable use of agricultural sandy soils, PROCEEDINGS OF THE 46 INTERNATIONAL SYMPOSIUM ON AGRICULTURAL ENGINEERING “Actual Tasks on Agricultural Engineering”, 2018, pp. 201211.

[19] Vlăduţoiu L., Cardei P., Vlăduţ V., Fechete L. - Modern trends in designing and selecting the machine/equipment for soil deep tillage, 16th International Scientific Conference "ENGINEERING FOR RURAL DEVELOPMENT”, ISSN 1691-5976, Jelgava, Latvia, 2017, pp. 1415-1420.

[20] Dragoș L., Principiile mecanicii analitice (Principles of analytical mechanics), Technical Publishing House: Editura Tehnică, București, 1976. 420 p. (In Romanian)

[21] Weisstein, Eric W. "Heaviside Step Function". MathWorld.[online], 2021. https://mathworld.wolfram.com/HeavisideStepFunction.html

[22] Rădoi M., Deciu E., Mecanica (Mechanics), Didactic and Pedagogical Publishing House: Editura Didactică și Pedagogică, București, 1981. 678 p. (In Romanian)

[23] Oprescu MR, Dumitru DN, Voicea IF, Biris SS, Considerations regarding the use of the equipment for opening and compartmentalizing the watering furrows, ISB-INMA-TEH, 2019.

[24] Oprescu MR, Biriș S.Ș., Voicea I., Cujbescu D., Gageanu I., Dumitru I., Considerations on the construction and operation of a device for soil modelling in interrupted furrows for weeding crops, TE-RE-RD, 2018, pp. 309-314.

[25] Letosnev M.N., Masini Agricole (Agricultural machines), State Agro-Forestry Publishing House : Editura Agro-Silvica de Stat, Bucuresti 1959. 595 p. (In Romanian)

[26] American Society of Agricultural Engineers [ASAE]. 2003a. D497.4 Agricultural machinery management data. In: ASAE. ASAE standards. ASAE, St. Joseph, MI, USA. 2003, pp. 373-380. 